\title{
Bailout rotational atherectomy in patients with myocardial infarction is not associated with an increased periprocedural complication rate or poorer angiographic outcomes in comparison to elective procedures (from the ORPKI Polish National Registry 2015-2016)
}

\author{
Rafał Januszek ${ }^{1}$, Zbigniew Siudak², Artur Dziewierz ${ }^{3}$, Tomasz Rakowski ${ }^{3}$, Jacek Legutko ${ }^{3}$, Dariusz Dudek ${ }^{4}$, \\ Stanisław Bartuś $\dot{s}^{3}$ \\ ${ }^{1} 2^{\text {nd }}$ Department of Cardiology, University Hospital, Krakow, Poland \\ ${ }^{2}$ Faculty of Medicine and Health Sciences, Jan Kochanowski University, Kielce, Poland \\ ${ }^{3} 2^{\text {nd }}$ Department of Cardiology, Jagiellonian University Medical College, Krakow, Poland \\ ${ }^{4}$ Department of Interventional Cardiology, Jagiellonian University Medical College, Krakow, Poland
}

Adv Interv Cardiol 2018; 14, 2 (52): 135-143

DOI: https://doi.org/10.5114/aic.2018.76404

\begin{abstract}
Introduction: Many years of experience and refinement of existing rotational atherectomy (RA) techniques have resulted in improved clinical outcomes and a tendency to broaden the spectrum of RA usage.

Aim: To compare the angiographic effectiveness and periprocedural complications in patients with stable angina (SA) and acute myocardial infarction (AMI) treated using RA.

Material and methods: Data were prospectively collected using the Polish Cardiovascular Intervention Society national registry (ORPKI) on all percutaneous coronary interventions (PCls) performed in Poland in 2015 and 2016. In total, 975 RA procedures were recorded out of 221,187 $\mathrm{PCl}$ procedures.

Results: We compared angiographic effectiveness and periprocedural complications in 530 patients with SA and 245 with AMI in the RA group of patients, and 60,522 patients with SA and 91,985 with AMI in the non-RA group. The overall rate of periprocedural complications did not differ between SA and AMI patients in the RA group (2.3\% vs. $2.0 \% ; p=0.84$ ), while it was lower in AMI patients from the RA group compared to those from the non-RA group $(2.0 \%$ vs. $3.0 \% ; p=0.34)$. The percentage of patients with angiographic success in the RA group was similar to the non-RA group in SA patients $(97.3 \%$ vs. $97.1 \% ; p=0.75)$, whereas in the AMI group it was significantly higher compared to the non-RA group $(96.7 \%$ vs. $92.6 \% ; p<0.001)$.

Conclusions: The angiographic effectiveness of $\mathrm{PCl}$ with RA in patients with AMI was not worse than in patients with SA.
\end{abstract}

Key words: percutaneous coronary intervention, angioplasty, acute myocardial infarction, rotablation, periprocedural complications, angiographic effectiveness.

\section{Introduction}

Nowadays, in Europe, there is an increasing percentage of older patients in the general population. Due to that tendency, an increasing number of patients with heavily calcified coronary artery stenoses undergo percutaneous coronary interventions (PCls). These lesions are a great challenge for successful percutaneous revascularization. Prevalence of coronary calcifications in patients undergoing $\mathrm{PCl}$ was estimated at $17 \%$ to $35 \%$ [1]. In selected patients, rotational atherectomy (RA) could serve as an alternative method for coronary artery by-pass grafting (CABG) operations. In accordance with the wider use of RA as a result of the improvement outcomes and procedural techniques, the range of indications also became wider [2]. We observe increased use of RA in acute coronary syndrome (ACS) patients

Corresponding author:

Stanisław Bartuś MD, PhD, 2 ${ }^{\text {nd }}$ Department of Cardiology, University Hospital, 17 Kopernika St, 31-501 Krakow, Poland, phone: +48 604 112699 , e-mail: stanislaw.bartus@uj.edu.pl

Received: 23.12.2017, accepted: 19.02.2018. 
including selected patients with ST-segment elevation myocardial infarction (STEMI) [3]. The appearance of this trend is present, even though the incidence of acute myocardial infarctions (AMI) decreases, and this trend is due to the drop in STEMI prevalence, while the incidence of non-ST-elevation myocardial infarctions increases slightly (NSTEMI) [4]. So far, it has been postulated that RA is relatively contraindicated in thrombogenic states such as ACS, especially in STEMI patients [5]. The use of RA in selected patients with STEMI and a patent culprit artery without thrombus blockade seems to be acceptable $[2,3]$.

\section{Aim}

In this study, we aimed to assess whether the periprocedural complication rate and angiographic efficacy are poorer in patients with $\mathrm{AMI}$ compared to stable angina (SA) when treated using $\mathrm{PCl}$ and $\mathrm{RA}$.

\section{Material and methods}

We analyzed prospectively collected national data from all patients who underwent $\mathrm{PCl}$ in Poland between January 2015 and December 2016. Data on PCI practice in Poland were obtained from the ORPKI Polish National dataset, which is coordinated nationwide by the Jagiellonian University Medical College in cooperation with the AISN PTK (Association of Cardiovascular Interventions, Polish Cardiac Society). The ORPKI registry and RA patients were characterized in previously published studies [3]. In the current study, we concentrated on periprocedural results due to the fact that we did no collect all in-hospital and follow-up data following discharge. In the Polish National dataset, the definition of most periprocedural complications is left to the discretion of the operators. The baseline characteristics as well as periprocedural and outcome data were collected. The decision to perform RA was at the operators' discretion at each center according to the current European Recommendations [5]. All RA procedures were performed using the Rotablator rotational atherectomy system. All clinical decisions, such as vascular access, burr size, and treatment with glycoprotein IIb/IIla inhibitors or bivalirudin were at the operators' discretion.

\section{Statistical analysis}

All continuous variables were evaluated with the Kolmogorov-Smirnov test for distribution. Continuous variables are presented as mean \pm standard deviation. Categorical variables are presented as numeric values and percentages. Continuous variables were compared using the two-tailed Student $t$-test and the Mann-Whitney $U$-test, whereas categorical variables were compared using the $\chi^{2}$ test. To identify predictors of TIMI flow grade 3 after $\mathrm{PCl}$, univariate and multivariate analyses were performed. Both univariate and multivariate regression models for major adverse cardiac and cerebrovascular events (MACCE) were constructed. A model based on the retrograde correction method was created. Statistical significance was accepted at a 0.05 level of probability. The statistical analyses were performed using Statistica 10.0 software (Dell Software, Inc., Round Rock, TX, USA) and SPSS Statistics 24 (IBM, USA).

\section{Results}

\section{Patients' characteristics}

The overall count of patients undergoing PCl in Poland in 2015 and 2016 was 221,187. Among them, there were 975 patients who underwent $\mathrm{PCl}$ with RA $(0.44 \%)$ and 220,212 patients without RA. In the RA group, there were 530 cases with SA at admission (54.3\%), which was a higher percentage compared to the non-RA group with 60,522 cases $(27.5 \% ; p<0.001)$, while there were 245

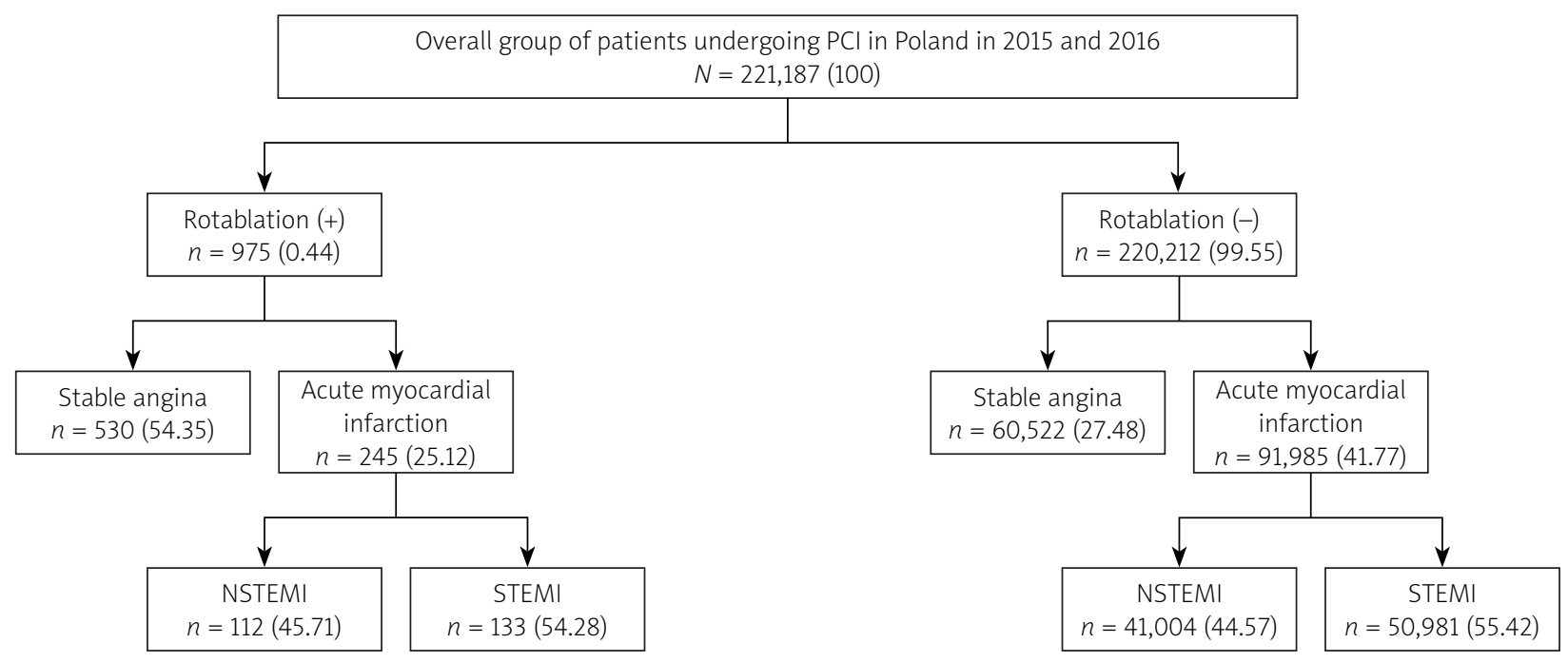

Figure 1. Subject flowchart 
(25.1\%) cases with AMI presentation of coronary artery disease (CAD) at admission, which was a significantly lower percentage as compared to the non-RA group of $91,985$ (41.8\%; $p<0.001)$. We also noted differences in the clinical presentation of CAD between the RA and non-RA groups. In the RA group, there was a higher percentage of patients with SA $(530 ; 54.8 \%)$ compared to the non-RA group $(60,522 ; 27.5 \% ; p<0.001)$, while the percentages of unstable angina (UA) $(19.3 \%$ vs. $29.8 \%$; $p<0.001)$, NSTEMI (11.6\% vs. $18.6 \% ; p<0.001)$ and STEMI $(13.7 \%$ vs. $23.2 \%$; $p<0.001)$ patients were significantly lower. We excluded from further analysis patients with symptoms of unstable angina before $\mathrm{PCl}$ in both investigated groups (Figure 1). Patients' characteristics and other indices including concomitant diseases, past percutaneous and cardiac procedures, as well as time of the procedure expressed as contrast dose and radiation exposure are presented in Table I.

\section{Periprocedural complications}

The rate of periprocedural complications was significantly higher in patients treated with RA compared to non-RA procedures in the SA group $(p=0.003)$, while in the AMI group there was no such difference $(p=0.35)$. The incidence of individual complications in all observed groups is presented in Table I.

Table I. Patients' characteristics

\begin{tabular}{|c|c|c|c|c|c|c|c|}
\hline \multirow[t]{2}{*}{ Variables } & \multirow[t]{2}{*}{ Overall group } & \multicolumn{2}{|c|}{ SA } & \multirow[t]{2}{*}{$P$-value } & \multicolumn{2}{|c|}{ AMI } & \multirow[t]{2}{*}{$P$-value } \\
\hline & & Rota (+) & Rota (-) & & Rota (+) & Rota (-) & \\
\hline Age [years] & $67.1 \pm 10.8$ & $71.4 \pm 9.2$ & $66.9 \pm 9.7$ & $<0.001$ & $73.1 \pm 10.4^{*}$ & $66.7 \pm 11.8^{\dagger}$ & $<0.001$ \\
\hline Gender, males & $150,140(67.9)$ & 391 (73.8) & $42,191(69.7)$ & 0.04 & $154(62.8)^{\star}$ & $62,058(67.5)$ & 0.12 \\
\hline Diabetes & $52,677(23.8)$ & 178 (33.6) & $15,828(26.1)$ & $<0.001$ & $84(34.3)$ & $19,918(21.6)^{\dagger}$ & $<0.001$ \\
\hline Hypertension & $157,408(71.2)$ & 409 (77.2) & $45,540(75.2)$ & 0.3 & 194 (79.2) & $60,499(65.8)^{\dagger}$ & $<0.001$ \\
\hline Past cerebral stroke & $7,290(3.3)$ & $16(3.1)$ & 1,876 (3.1) & 0.98 & $15(6.1)^{\star}$ & $3,289(3.6)$ & 0.03 \\
\hline Previous MI & 68,955 (31.2) & $280(52.8)$ & $25,661(42.4)$ & $<0.001$ & $125(51.0)$ & $20,294(22.1)^{\dagger}$ & $<0.001$ \\
\hline Previous PCI & $82,444(37.3)$ & $345(65.5)$ & $33,298(55.0)$ & $<0.001$ & $121(49.4)^{\star}$ & $20,290(22.0)^{\dagger}$ & $<0.001$ \\
\hline Previous CABG & $14,092(6.4)$ & $90(17.0)$ & 4,336 (7.2) & $<0.001$ & 29 (11.8) & $3,862(4.2)^{\dagger}$ & $<0.001$ \\
\hline Current smoker & 42,574 (19.2) & 79 (14.9) & 9,099 (15.0) & 0.93 & 29 (11.8) & $22,195(24.1)^{\dagger}$ & $<0.001$ \\
\hline Kidney failure & $12,127(5.5)$ & $58(10.9)$ & $3,458(5.7)$ & $<0.001$ & $36(14.7)$ & $5,088(5.5)$ & $<0.001$ \\
\hline COPD & $5,594(2.5)$ & $18(3.4)$ & $1,531(2.5)$ & 0.2 & $5(2.0)$ & $2,373(2.6)$ & 0.59 \\
\hline \multicolumn{8}{|l|}{ Complications: } \\
\hline Overall/patient & 4,266 (1.9) & $12 / 530(2.3)$ & $596(1.0)$ & 0.003 & $5 / 245(2.0)$ & $2,804(3.0)^{\dagger}$ & 0.35 \\
\hline Overall/complication & $4,776(2.1)$ & 14/530 (2.6) & $644(1.1)$ & $<0.001$ & $6 / 245(2.4)$ & $3,384(3.7)^{\dagger}$ & 0.3 \\
\hline Arterial dissection & $234(0.1)$ & 0/96 (0) & $59(0.1)$ & 0.7 & 0/35 (0) & $96(0.1)$ & 0.83 \\
\hline CAP & $393(0.2)$ & $4 / 530(0.7)$ & $103(0.2)$ & 0.001 & 2/245 (0.8) & $174(0.2)$ & 0.02 \\
\hline Cardiac arrest & 1,413 (0.6) & 3/530 (0.6) & $91(0.1)$ & 0.01 & 2/245 (0.8) & $1,101(1.2)^{\dagger}$ & 0.58 \\
\hline Death & $1,018(0.5)$ & 0/530 (0) & $24(0.04)$ & 0.64 & 0/245 (0) & $842(0.9)^{\dagger}$ & 0.13 \\
\hline Allergic reaction & $354(0.2)$ & $1(0.2)$ & $120(0.2)$ & 0.96 & $0(0)$ & $135(0.1)$ & 0.54 \\
\hline Cerebral stroke & $18(0.01)$ & $0(0)$ & $3(0.01)$ & 0.84 & $0(0)$ & $12(0.01)$ & 0.85 \\
\hline Puncture-site bleeding & $223(0.1)$ & $2(0.4)$ & $52(0.08)$ & 0.02 & $0(0)$ & $104(0.1)$ & 0.59 \\
\hline \multicolumn{8}{|l|}{ Time of the procedure: } \\
\hline Radiation [mGy] & $1,071.6 \pm 965.1$ & $\begin{array}{r}1,763.0 \\
\pm 1,387.8\end{array}$ & $1,015.4 \pm 936.0$ & $<0.001$ & $\begin{array}{c}1,516.5 \\
\pm 1,030.1\end{array}$ & $\begin{array}{c}1,106.7 \\
\pm 1,016.2^{\dagger}\end{array}$ & $<0.001$ \\
\hline Contrast [ml] & $176.2 \pm 79.0$ & $221.1 \pm 96.5$ & $169.8 \pm 79.3$ & $<0.001$ & $225.9 \pm 100.6$ & $180.1 \pm 79.0^{\dagger}$ & $<0.001$ \\
\hline
\end{tabular}

Data are expressed as mean $\pm S D$ or numbers (percentages). Student's t-test or the Mann-Whitney $U$ test was used for continuous variables, and the $\chi^{2}$ test was used for categorical variables. CABG - coronary artery bypass grafting surgery, CAP - coronary artery perforation, COPD - chronic obstructive pulmonary disease, $\mathrm{MI}-$ myocardial infarction, $\mathrm{PCl}-$ percutaneous coronary intervention. ${ }^{*} p<0.05$ when SA and AMI patients were compared in the RA (+) group. ${ }^{t} p<0.05$ when $S A$ and $A M I$ patients were compared in the RA (-) group. 


\section{Angiographic effectiveness and procedural success}

The percentage of patients with thrombolysis in myocardial infarction (TIMI) grade 3 flow was significantly higher in the non-RA group compared to the RA group at baseline $(59.9 \%$ vs. $66.8 \%, p=0.002)$ in SA patients, while it was significantly higher in the RA group compared to the non-RA in AMI patients ( $45.8 \%$ vs. $29.2 \%$, $p<0.001$ ). The percentage of patients with TIMI grade 0 flow at baseline was significantly lower in the AMI group in RA patients compared to non-RA patients ( $9.2 \%$ vs. $38.3 \%$; $p<0.001$; Figure 2 A).
A

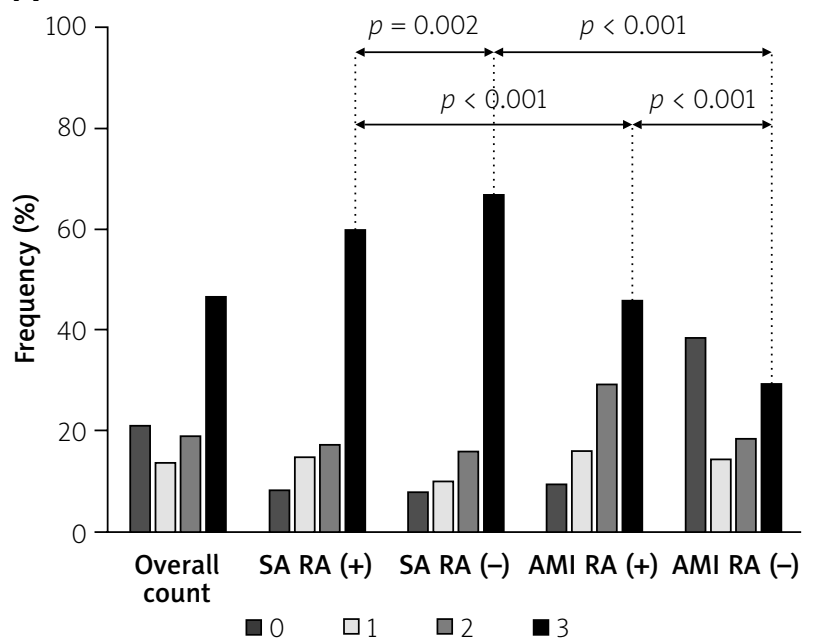

B

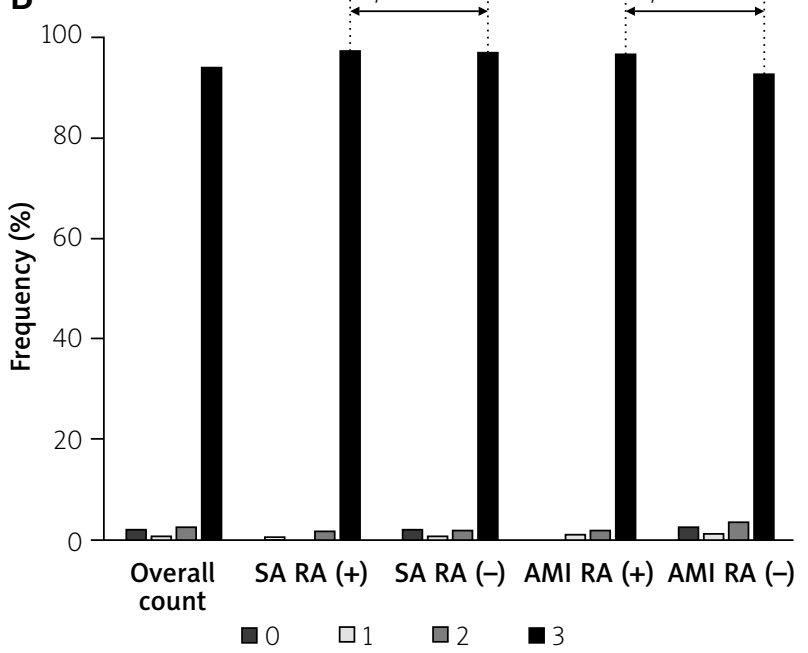

Figure 2. A - Distribution of TIMI flow grade (0-3) percentages before percutaneous coronary intervention in the overall group of patients, stable angina (RA-), stable angina (RA+), acute myocardial infarction (RA-) and acute myocardial infarction (RA+). B - Distribution of TIMI flow grade (0-3) percentages after percutaneous coronary intervention in the overall group of patients, stable angina (RA-), stable angina (RA+), acute myocardial infarction (RA-) and acute myocardial infarction (RA+)

Table II. Procedural indices

\begin{tabular}{|c|c|c|c|c|c|c|c|}
\hline \multirow[t]{2}{*}{ Variables } & \multirow[t]{2}{*}{ Overall group } & \multicolumn{2}{|c|}{ SA } & \multirow[t]{2}{*}{$P$-value } & \multicolumn{2}{|c|}{ AMI } & \multirow[t]{2}{*}{$P$-value } \\
\hline & & Rota (+) & Rota (-) & & Rota (+) & Rota $(-)$ & \\
\hline \multicolumn{8}{|l|}{ Angiography: } \\
\hline Single-vessel disease & 138,701 (69.0) & $324(72.0)$ & $40,405(74.0)$ & 0.33 & $41(51.9)^{\star}$ & $51,825(64.7)^{\dagger}$ & 0.02 \\
\hline MVD, LMCA (-) & $52,256(26.0)$ & $72(16.0)$ & $11,992(21.9)$ & 0.002 & $26(32.9)^{\star}$ & $23,794(29.7)^{\dagger}$ & 0.53 \\
\hline MVD, LMCA (+) & $8,100(4.0)$ & 45 (10.0) & $1,706(3.1)$ & $<0.001$ & $10(12.6)$ & $3,839(4.8)^{\dagger}$ & 0.001 \\
\hline Isolated LMCA & $1,819(0.9)$ & $9(2.0)$ & $510(0.9)$ & 0.02 & $2(2.5)$ & $611(0.8)$ & 0.07 \\
\hline \multicolumn{8}{|l|}{ Vascular access: } \\
\hline Femoral artery & $56,636(25.6)$ & $174(32.8)$ & $13,604(22.5)$ & $<0.001$ & $113(46.1)^{*}$ & $25,277(27.5)^{\dagger}$ & $<0.001$ \\
\hline Left radial artery & $36,799(16.6)$ & $53(10.0)$ & $10,423(17.2)$ & $<0.001$ & $23(9.4)$ & $14,604(15.9)$ & 0.005 \\
\hline Right radial artery & $126,129(57.0)$ & $297(56.0)$ & $35,979(59.4)$ & 0.11 & $108(44.1)^{\star}$ & $51,513(56.0)^{\dagger}$ & $<0.001$ \\
\hline Other & $1,643(0.7)$ & $6(1.1)$ & $516(0.8)$ & 0.48 & $1(0.4)$ & $591(0.6)$ & 0.64 \\
\hline Bifurcation & $11,894(5.4)$ & $49(9.2)$ & $4,058(6.7)$ & 0.02 & $14(5.7)$ & $4,029(4.4)^{\dagger}$ & 0.3 \\
\hline Chronic total occlusion & $9,320(4.2)$ & $31(5.8)$ & $3,775(6.2)$ & 0.71 & $10(4.1)$ & $2,757(3.0)^{\dagger}$ & 0.32 \\
\hline Fractional flow reserve & $3,258(1.5)$ & $9(1.7)$ & $2,348(3.9)$ & 0.009 & $1(0.4)$ & $283(0.3)^{\dagger}$ & 0.77 \\
\hline Intravascular ultrasound & $1,882(0.8)$ & $24(4.5)$ & $976(1.6)$ & $<0.001$ & $7(2.8)$ & $439(0.5)^{\dagger}$ & $<0.001$ \\
\hline OCT & $400(1.8)$ & $3(0.6)$ & $210(0.3)$ & 0.39 & $2(0.8)$ & $89(0.1)^{\dagger}$ & $<0.001$ \\
\hline
\end{tabular}

Data are expressed as numbers (percentages). Student's t-test or the Mann-Whitney U test was used for continuous variables, and the $\chi^{2}$ test was used for categorical variables. LMCA - left main coronary artery, MVD - multi-vessel disease, OCT - optical coherence tomography. ${ }^{*} p<0.05$ when SA and AMI patients were compared in the RA (+) group. ${ }^{+} p<0.05$ when SA and AMI patients were compared in the $R A(-)$ group. 
After $\mathrm{PCl}$, the percentage of patients with TIMI grade 3 flow in the RA group was similar to the non-RA group in SA patients ( $97.3 \%$ vs. $97.1 \%, p=0.75)$ and to the RA group with AMI (97.3\% vs. $96.7 \% ; p=0.62)$. However, the percentage of patients with TIMI grade 3 flow in the AMI group treated with RA was higher than in the nonRA group ( $96.7 \%$ vs. $92.6 \% ; p<0.001$; Figure 2 B). We were not able to assess procedural success due to the lack of specific data. It was indirectly determined based on the performed type of $\mathrm{PCl}$. The group of patients with plain old balloon angioplasty (POBA) and failed $\mathrm{PCl}$ could be considered as representing unsuccessful procedures. On this basis, the rate of failed RA procedures was significantly lower in SA compared to AMI patients $(1.9 \%$ vs. $6.9 \% ; p<0.001)$. A similar relationship was noted in the non-RA group when comparing SA and AMI patients (6.7\% vs. $8.9 \% ; p<0.001)$. The frequency of POBA/failed $\mathrm{PCl}$ in the RA group was lower in this group as compared to the non-RA in SA and AMI groups (Table II).

\section{Lesion characteristics}

Both in the SA and AMI groups, $\mathrm{PCl}$ of the left main coronary artery (LMCA) was more often performed in the RA group compared to the non-RA group $(p<0.001)$. The rate of drug-eluting stent (DES) restenosis and bare-metal stent (BMS) restenosis was significantly lower in the RA group compared to the non-RA group in SA patients, whereas it was not significantly lower in AMI patients (Figure $3 \mathrm{~A}$ ). De-novo lesions were more often treated in the RA group compared to the non-RA group ( $p<0.001$ ), while restenosis lesions were less often treated in RA pa-

A

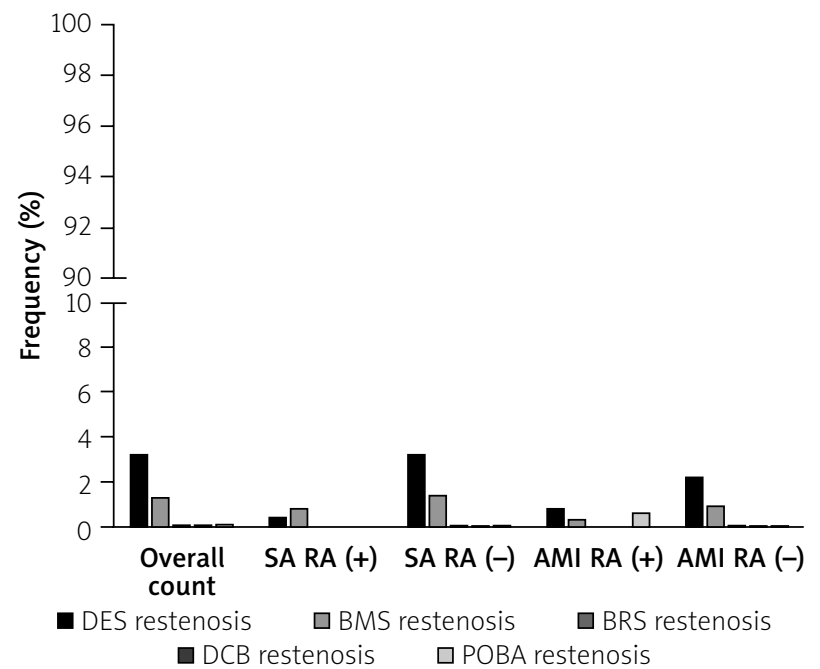

tients ( $p<0.001$ ), in the SA and AMI groups (Figure 3 B). Location of culprit arteries is presented in Table III.

\section{Procedure characteristics}

All procedural indices including coronary angiography, vascular access, lesion type and additional devices used during the $\mathrm{PCl}$ are presented in Table II.

\section{Predictors of TIMI grade 3 flow after PCI}

Multivariable analysis revealed that the positive predictors of TIMI grade 3 flow after $\mathrm{PCl}$ in the overall group of patients undergoing RA included older age (odds ratio $(\mathrm{OR})=1.037$; 95\% confidence interval $(\mathrm{Cl}): 1.029-1.045$; $p<0.001$ ) and patent culprit artery (TIMI grade 2 or 3 flow) before $\mathrm{PCI}(\mathrm{OR}=3.76$; $95 \% \mathrm{Cl}$ : 1.823-7.755; $p<0.001)$. In the SA group of patients treated with RA, the positive predictors of TIMI grade 3 flow after $\mathrm{PCI}$ also included older age $(\mathrm{OR}=1.038 ; 95 \% \mathrm{Cl}$ : 1.027-1.049; $p<0.001$ ) and patent culprit artery (TIMI grade 2 or 3 flow) before $\mathrm{PCl}(\mathrm{OR}=4.169 ; 95 \% \mathrm{Cl}: 1.5-11.593 ; p=$ 0.06). Among the positive predictors of TIMI grade 3 flow after $\mathrm{PCl}$ in patients with $\mathrm{AMI}$ treated with RA we also confirmed older age $(\mathrm{OR}=1.035 ; 95 \% \mathrm{Cl}: 1.022-1.049$; $p<0.001$ ), whereas the patent culprit artery (TIMI grade 2 or 3 flow) before $\mathrm{PCl}$ was only of borderline significance $(\mathrm{OR}=3.691 ; 95 \% \mathrm{Cl}: 0.95-14.345 ; p=0.059)$.

\section{Discussion}

The main finding of the current study is that the use of RA in selected patients with AMI may not increase the periprocedural complication rate and is not associated

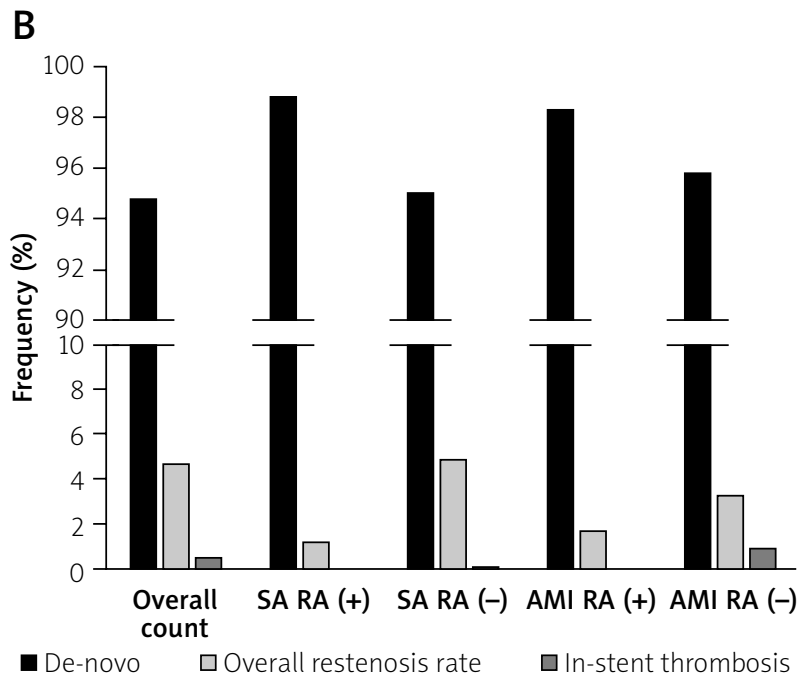

Figure 3. A - Distribution of DES-, BMS-, BRS-, DCB- and POBA-restenosis percentages in the overall group of patients, stable angina (RA-), stable angina (RA+), acute myocardial infarction (RA-) and acute myocardial infarction (RA+). B - Distribution of de-novo lesion, restenosis and in-stent thrombosis percentages in the overall group of patients, stable angina (RA-), stable angina (RA+), acute myocardial infarction (RA-) and acute myocardial infarction (RA+)

$B M S$ - bare-metal stent, BRS - bioresorbable scaffold, DCB - drug-coated balloon, DES - drug-eluting stent, POBA - plain old balloon angioplasty. 
Table III. Location of culprit lesion, type of $\mathrm{PCl}$ and periprocedural complications

\begin{tabular}{|c|c|c|c|c|c|c|c|}
\hline \multirow[t]{2}{*}{ Variable } & \multirow[t]{2}{*}{ Overall group } & \multicolumn{2}{|c|}{ SA } & \multirow[t]{2}{*}{$P$-value } & \multicolumn{2}{|c|}{ AMI } & \multirow[t]{2}{*}{$P$-value } \\
\hline & & Rota (+) & Rota (-) & & Rota (+) & Rota (-) & \\
\hline \multicolumn{8}{|l|}{ Culprit artery: } \\
\hline $\begin{array}{l}\text { Left main coronary } \\
\text { artery }\end{array}$ & $6,697(3.2)$ & $56(10.6)$ & $1,672(3.0)$ & $<0.001$ & $41(16.7)^{\star}$ & $2,740(3.1)$ & $<0.001$ \\
\hline $\begin{array}{l}\text { Left anterior } \\
\text { descending artery }\end{array}$ & $79,411(38.3)$ & $226(42.6)$ & $20,954(37.5)$ & 0.01 & $109(44.5)$ & $33,606(38.6)^{\dagger}$ & 0.06 \\
\hline Circumflex artery & $47,183(22.7)$ & $106(20.0)$ & $13,603(24.3)$ & 0.02 & 47 (19.2) & $18,792(21.6)^{\dagger}$ & 0.36 \\
\hline Intermediate artery & $3,451(1.7)$ & $2(0.4)$ & $1,041(1.9)$ & 0.01 & $3(1.2)$ & $1,298(1.5)^{\dagger}$ & 0.73 \\
\hline Right coronary artery & $67,618(32.6)$ & $181(34.1)$ & $17,895(32.0)$ & 0.29 & $71(29.0)$ & $29,629(34.0)^{\dagger}$ & 0.09 \\
\hline Saphenous vein graft & 2,616 (1.3) & $1(0.2)$ & $582(1.0)$ & 0.05 & $0(0)$ & $940(1.1)$ & 0.1 \\
\hline $\begin{array}{l}\text { Internal mammary } \\
\text { artery }\end{array}$ & $442(0.2)$ & $0(0)$ & $114(0.2)$ & 0.29 & $0(0)$ & $134(0.1)^{\dagger}$ & 0.53 \\
\hline \multicolumn{8}{|l|}{ Type of PCl: } \\
\hline Drug-eluting stent & $189,553(85.7)$ & $507(95.7)$ & $52,908(87.4)$ & $<0.001$ & $221(90.2)^{*}$ & $77,317(84.0)^{\dagger}$ & 0.008 \\
\hline Bare-metal stent & $7,271(3.3)$ & $0(0)$ & $1,089(1.8)$ & 0.002 & $3(1.2)^{*}$ & $4,304(4.7)^{\dagger}$ & 0.01 \\
\hline Bioresorbable scaffold & $2,934(1.3)$ & $3(0.6)$ & $1,100(1.8)$ & 0.03 & $6(2.4)^{*}$ & $1,028(1.1)^{\dagger}$ & 0.04 \\
\hline Drug-coated balloon & $4,834(2.2)$ & $11(2.1)$ & $1,477(2.4)$ & 0.58 & $2(1.2)$ & $1,564(1.7)^{\dagger}$ & 0.28 \\
\hline POBA/failed & $17,249(7.8)$ & $10(1.9)$ & $4,070(6.7)$ & $<0.001$ & $17(6.9)^{\star}$ & $8,151(8.9)^{\dagger}$ & 0.28 \\
\hline
\end{tabular}

Data are expressed as numbers (percentages). The $\chi^{2}$ test was used for categorical variables. $P C I$ - percutaneous coronary intervention, POBA - plain old balloon angioplasty. ${ }^{*} p<0.05$ when SA and AMI patients were compared in the RA (+) group. ${ }^{\dagger} p<0.05$ when SA and AMI patients were compared in the RA (-) group.

with poorer angiographic efficacy compared to patients with SA. Moreover, the angiographic success rate in patients with $\mathrm{AMI}$ treated with RA was higher as compared to patients with AMI from the non-RA group.

Despite the fact that intra-arterial thrombus is recognized as a contraindication to RA in AMI patients, especially in STEMI patients, the use of RA in this group is becoming more and more widespread [6]. It is associated, among other reasons, with the evolution of the profile of patients and culprit lesions in countries with well-developed networks of interventional cardiology facilities and frequent PCls. Recently in these countries, STEMI patients more often present complex and calcified target lesions, they suffer from many comorbidities and are at increased risk of cardiac operations. Due to this, those patients are being transferred from the CABG group to the $\mathrm{PCl}$ with RA group more often in recent years, especially when they are unstable and regular devices are not able to cross well-calcified lesions.

\section{Periprocedural complications}

Periprocedural complications typical for RA are similar to those common for $\mathrm{PCl}$ and include vascular access complications, stroke, MI, urgent CABG surgery, death, coronary artery perforation (CAP), artery dissection (AD), short-term closure, side branch loss and the slow-flow/no-reflow phenomenon [7]. The frequency of these periprocedural complications depends on several factors, with the most influential including type of $\mathrm{PCl}$, study population and year of study [6]. In recent years,
RA techniques have changed. Smaller burr sizing reduces angiographic complications [5, 8, 9]. The incidence of particular complications in patients undergoing RA is estimated at $0-4 \%$ for death, $1-19.8 \%$ for $\mathrm{MI}, 0-0.8 \%$ for urgent $C A B G, 1.7-5.9 \%$ for $C A D, 0-2 \%$ for CAP and $0-2.6 \%$ for slow flow/no-reflow [10-12]. Complications typical for RA include vasospasm (1.6\% to 6.6\%) and burr entrapment $(0.5 \%$ to $1 \%)$. However, a recently published study including a large number of participants $(13,335$ RA cases) reported that primary composite outcomes, including in-hospital death, tamponade, and emergent surgery, occurred in $1.31 \%$ of patients [13]. Most available publications reported predictors of periprocedural complications in the overall group of patients treated with RA. For example, it was demonstrated that women and older patients were at increased risk of CAP [14]. Additional risk factors include the use of clopidogrel, kidney failure, hypertension, previous CABG, history of congestive heart failure including dialysis therapy, peripheral vascular disease, ACC/AHA type C lesion, radial access and multi-vessel disease (MVD) [14]. Rotational atherectomy was also found to be an independent predictor of CAP in the overall group of patients undergoing $\mathrm{PCl}$ [3]. We presented the results concerning predictors of selected periprocedural complications in the overall group of patients treated with RA in a previously published study [4]. Critics of RA $\mathrm{PCl}$ focus on the high complication rates reported in older trials and registries. However, data reported by Sakakura et al. were provided in 2014 and 2015 and come from Japan, where interventional cardiology is recognized to 
be well developed [13]. Nevertheless, RA strategies in the past included large burr diameters, high burr speeds, large caliber catheters and no dual antiplatelet therapy or DES therapies enabling productive comparisons. Several studies compared periprocedural complication rates between RA patients and non-RA patients, as well as the different $\mathrm{PCl}$ technologies. For example, Cockburn et al. reported that selected complications occurred more often in the RA group such as AD (3.6\% vs. $2.2 \%$; $p<0.001)$, CAP $(1.1 \%$ vs. $0.3 \% ; p<0.001)$, cardiac tamponade $(0.2 \%$ vs. $0.1 \% ; p=0.02)$, and non-Q wave MI ( $1.1 \%$ vs. $0.4 \%$; $p<0.001$ ) [15]. A review by Cavusoglu et al. listed the following complication rates: death $1 \%$, emergency CABG 1-2\%, abrupt vessel closure 10-13\%)and CAP 1.5\% [7]. Another study completed by Kawamoto et al. included 1,076 consecutive patients treated with RA [16]. Exclusion criteria included recent STEMI and lesions with angiographic evidence of thrombus. The leading complication was residual AD (7.0\%). CAP was observed in 1.0\% of all cases, and 1 patient died. The rate of periprocedural complications was lower in the BMS group (2.6\%) then in the DES group (2.4\%) [8]. The study published by Rathore et al. demonstrated an acceptable in-hospital MACE rate (8.3\%) when only considering patients receiving newer-generation DES following RA. In support of previous studies, the rate of in-hospital MACE was principally driven by periprocedural MI, while the mortality rate was low $(0.6 \%)$ [11]. Similar relationships were presented in other studies $[12,17]$. Rotational atherectomy was used more frequently for LMCA intervention. The higher percentage of $L M C A P C I$ shows an increased rate of patients transferred from the CABG group and higher perioperative risk. It could be suspected that it should worsen clinical and procedural outcomes in comparison to regular patients undergoing $\mathrm{PCl}$. This highlights the complexity of many RA interventions. The higher incidence of the elective intra-aortic balloon pump procedural support in the RA group compared to the non-RA group could be proof of this [15]. One of the few published studies comparing the use of RA in patients with NSTEMI and SA was the registry published by lannaccone et al., which included 1,308 patients, $37 \%$ in the NSTEMI group and $63 \%$ in the SA group. Procedural complications were more frequent in the NSTEMI group compared with the SA group, driven mainly by a higher rate of slow flow/no-flow (3.3\% vs. $1.4 \% ; p=0.02$ ), while in-hospital death and MACE did not differ significantly (1.2\% vs. $0.3 \%$ and $5.7 \%$ vs. 5.8\%) [18] The largest study on RA, published by Sakakura et al., demonstrated that among others well-known factors related to increased rate of periprocedural complications such as age, gender, kidney function, number of diseased vessels, and volume of the institution, there was also emergent $\mathrm{PCl}$, which increased the probability of composite study endpoints almost four times [13]. Our analysis revealed different results. It could be due, at least in part, to the higher rate of periprocedural complications in patients with unstable angina (2.7\%). Those patients were excluded from the current analysis. Also, it is difficult to compare the patients' characteristics with our study, because they compared complication and non-complication groups, which could substantially blur the conclusions. The frequency of RA use in Japan is greater than that in Poland, which may also reflect better operator's skills in performing RA procedures. Another issue is that culprit lesions in AMI patients qualified for RA are partially prepared for $\mathrm{PCl}$. The artery has to be patent enough for the guidewire's passage. This, by definition, reduces the risk of periprocedural complications in comparison to regular $\mathrm{PCl}$ in $\mathrm{AMI}$ patients.

\section{Angiographic and procedural effectiveness}

The procedural success of RA in published studies ranges from $72.2 \%$ to $100 \%$. It depends on the type of $\mathrm{PCl}$ and the year of the study. The improvement in results in recent years is attributed to modern techniques and new equipment $[19,20]$. For example, Benezet et al. published a study in a group of patients treated with RA, which included 102 patients at the mean age of 68.8 years. The procedure was successful in 97\% [10]. Cockburn et al. compared the clinical outcomes of RA and non-RA PCI procedures performed in the UK, which included 2,125 patients after RA from a total of 221,669 patients undergoing PCl. Patients undergoing RA procedures were older (71.7 vs. 64.1 years; $p<0.001$ ) and suffered from concomitant diseases more often, which was also similar in our group of patients. Furthermore, clinical presentation of CAD, vascular access and the frequencies of particular culprit arteries were similar to the results obtained in our study [15]. Procedural success was poorer in the RA group compared to the non-RA group (90.3\% vs. 94.6\%; $p<0.001)$ [15]. Rathore et al. compared procedural outcomes and angiographic follow-ups in a group of $516 \mathrm{pa}$ tients treated with RA [11]. Angiographic success (defined as $<30 \%$ residual stenosis and TIMI grade 3 flow) was achieved in $97.1 \%$ of cases. Another study reported that angiographic success (defined as 20\% residual stenosis and TIMI grade 3 flow) was achieved in $96.7 \%$ of cases in both groups [12]. In the study published by Kawamoto et al., final TIMI grade 3 flow was achieved in $99.1 \%$ of patients even though slow- or no-flow was observed in $1.1 \%$ [16]. In their analyses, most of the published studies compared patients treated with RA and regular $\mathrm{PCl}$, or with a different type of stents, or stents in comparison to POBA. Only a few studies have compared SA with other clinical presentations of CAD. lannaccone et al. reported that the mean post-procedure TIMI grade flow $(2.9 \pm 0.3$ vs. $2.98 \pm 0.2 ; p=0.058)$ and angiographic success $(98.8 \%$ vs. $99.2 \%, p=0.57$ ) were not significantly different [18]. However, despite the fact that the authors compared the NSTEMI and SA groups, the indication for RA was elec- 
tive in about half of the cases in both groups (49.2\% vs. $50.9 \% ; p=0.73$ ). This was different than in our population, where patients in the SA group were all elective, whereas in the STEMI group, all were urgent. It was demonstrated that vasculopathy, MVD, bifurcation lesions and low TIMI grade flow were among the independent predictors for RA in bailout cases [18]. We did not perform multivariable analysis of factors influencing bailout RA due to the fact that it would be the equivalent of AMI predictors in the RA group. Similar results were obtained in the DART trial, which achieved a procedural success rate of 91.6\% [17]. A more recent paper published by Benezet et al. reported comparable angiographic success as our data [10]. Tamura et al. compared BMS implantation with DES implantation, where angiographic success was $100 \%$ in both groups, while the procedural success was $96.6 \%$ and $97.2 \%$, respectively [19]. The high angiographic effectiveness of RA for the STEMI group in the current study can certainly be attributed to the natural exclusion of patients with a large thrombus load and the consequent inability to visualize some parts of the culprit artery due to slowflow or no-reflow. On the other hand, STEMI patients with multi-segmental and calcified atherosclerosis, and who are more likely to undergo $\mathrm{PCl}$ of the LMCA and LAD, are at increased procedural risk at baseline. Another issue is that the angiographic effectiveness was higher in RA patients with AMI compared to procedural effectiveness. First, angiographic effectiveness assessed as TIMI grade 3 flow after the procedure does not mean that the procedure was effective. We are not in possession of exact data on procedural effectiveness. It was estimated as POBA and failed $\mathrm{PCl}$, whereas POBA does not always mean that the procedure was not effective in all cases. Among predictors of angiographic effectiveness we found TIMI flow before $\mathrm{PCl}$ and age. While poorer TIMI flow before $\mathrm{PCl}$ could obviously impact the final effectiveness, worse angiographic effectiveness in younger patients remains unclear. Possibly, it could be explained by the low number of patients with impaired TIMI flow after $\mathrm{PCl}$ and those dichotomous variables could be over-fitted.

The decision whether to perform RA or not was at the operators' discretion. Definitions of periprocedural complications also depended on the operators. No propensity score matching analysis was performed due to limited availability of angiographic data including calcification severity, vessel size, thrombus load, etc. Underreported periprocedural complications including periprocedural myocardial infarctions and no-reflows were removed from the analysis. Estimation of the number of no-reflows in a selected group of AMI patients treated with RA is difficult and largely depends on the operator. Also, it seems that finally greater TIMI grade 3 flow in RA patients compared to non-RA in the AMI group is substantially influenced by the specific bias selection. The RA procedure could be performed in patients where the guidewire has crossed the lesion and an unsuccessful attempt of predilatation was undertaken. If the guidewire did not cross the culprit lesion, the operators could not use RA.

\section{Conclusions}

Rotational atherectomy used during urgent $\mathrm{PCl}$ in patients with AMI facilitates complex procedures rather than increasing the periprocedural complication rate or contributing to poorer angiographic procedural results when compared to the treatment of patients with SA in an elective manner.

\section{Conflict of interest}

The authors declare no conflict of interest.

\section{References}

1. Kawaguchi R, Tsurugaya $\mathrm{H}$, Hoshizaki $\mathrm{H}$, et al. Impact of lesion calcification on clinical and angiographic outcome after sirolimus-eluting stent implantation in real-world patients. Cardiovasc Revasc Med 2008; 9: 2-8.

2. Bartuś S, Januszek R, Legutko J, et al. Long-term effects of rotational atherectomy in patients with heavy calcified coronary artery lesions: a single-centre experience. Kardiol Pol 2017; 75: 564-72.

3. Januszek R, Siudak Z, Dziewierz A, et al. Predictors of in-hospital effectiveness and complications of rotational atherectomy (from the ORPKI Polish National Registry 2014-2016). Catheter Cardiovasc Interv 2017 in press doi: 10.1002/ccd.27372.

4. Yeh RW, Sidney S, Chandra M, et al. Population trends in the incidence and outcomes of acute myocardial infarction. N Engl J Med 2010; 362: 2155-65.

5. Barbato E, Carrié D, Dardas P, et al.; European Association of Percutaneous Cardiovascular Interventions. European expert consensus on rotational atherectomy. Eurolntervention 2015; 11: 30-6.

6. Tomey MI, Kini AS, Sharma SK. Current status of rotational atherectomy. JACC Cardiovasc Interv 2014; 7: 345-53.

7. Cavusoglu E, Kini AS, Marmur JD, et al. Current status of rotational atherectomy. Catheter Cardiovasc Interv 2004; 62: 485-98.

8. Safian RD, Feldman T, Muller DW, et al. Coronary Angioplasty and Rotablator Atherectomy Trial (CARAT). Immediate and late results of a prospective multicenter randomized trial. Catheter Cardiovasc Interv 2001; 53: 213-20.

9. Doyle BJ, Ting HH, Bell MR, et al. Major femoral bleeding complications after percutaneous coronary intervention: incidence, predictors, and impact on long-term survival among 17,901 patients treated at the Mayo Clinic from 1994 to 2005. JACC Cardiovasc Interv 2008; 1: 202-9.

10. Benezet J, Diaz de la Llera LS, Cubero JM, et al. Drug-eluting stents following rotational atherectomy for heavily calcified coronary lesions: long-term clinical outcomes. J Invasive Cardiol 2011; 23: 28-32.

11. Rathore S, Matsuo H, Terashima M, et al. Rotational atherectomy for fibro-calcific coronary artery disease in drug eluting stent era: procedural outcomes and angiographic follow-up results. Catheter Cardiovasc Interv 2010; 75: 919-27.

12. Abdel-Wahab M, Richardt $G$, Joachim Büttner $H$, et al. Highspeed rotational atherectomy before paclitaxel-eluting stent 
implantation in complex calcified coronary lesions: the randomized ROTAXUS (Rotational Atherectomy Prior to Taxus Stent Treatment for Complex Native Coronary Artery Disease) trial. JACC Cardiovasc Interv 2013; 6: 10-9.

13. Sakakura K, Inohara T, Kohsaka S, et al. Incidence and determinants of complications in rotational atherectomy: insights from the National Clinical Data (J-PCI Registry). Circ Cardiovasc Interv 2016; 9: pii: e004278.

14. Fasseas P, Orford JL, Panetta CJ, et al. Incidence, correlates, management, and clinical outcome of coronary perforation: analysis of 16,298 procedures. Am Heart J 2004; 147: 140-5.

15. Cockburn J, Hildick-Smith D, Cotton J, et al. Contemporary clinical outcomes of patients treated with or without rotational coronary atherectomy: an analysis of the UK central cardiac audit database. Int J Cardiol 2014; 170: 381-7.

16. Kawamoto H, Latib A, Ruparelia N, et al. In-hospital and midterm clinical outcomes of rotational atherectomy followed by stent implantation: the ROTATE multicentre registry. Eurolntervention 2016; 12: 1448-56.

17. Mauri L, Reisman M, Buchbinder M, et al. Comparison of rotational atherectomy with conventional balloon angioplasty in the prevention of restenosis of small coronary arteries: results of the Dilatation vs Ablation Revascularization Trial Targeting Restenosis (DART). Am Heart J 2003; 145: 847-54.

18. Iannaccone M, Piazza F, Boccuzzi GG, et al. ROTational AThErectomy in acute coronary syndrome: early and midterm outcomes from a multicentre registry. Eurolntervention 2016; 12: 1457-64.

19. Tamura H, Miyauchi K, Dohi T, et al. Comparison of clinical and angiographic outcomes after bare metal stents and drug-eluting stents following rotational atherectomy. Int Heart J 2016; 57: 150-7.

20. Sharma SK, Kini A, Mehran R, et al. Randomised trial of rotational atherectomy versus balloon angioplasty for diffuse in-stent restenosis (ROOSTER). Am Heart J 2004; 147: 16-22. 